\title{
Addressing challenging behaviour in children with Down syndrome: The use of applied behaviour analysis for assessment and intervention
}

\author{
Kathleen M. Feeley and Emily A. Jones
}

\section{C.W. Post Campus of Long Island University, USA}

\begin{abstract}
Children with Down syndrome are at an increased risk for engaging in challenging behaviour that may be part of a behavioural phenotype characteristic of Down syndrome. The methodology of applied behaviour analysis has been demonstrated effective with a wide range of challenging behaviours, across various disabilities. Applications to children with Down syndrome and the examination of behaviourally based strategies to specifically address the unique characteristics of children with Down syndrome are limited. However, there are several studies in which a subset of the participants did have Down syndrome. A handful of these studies are reviewed within the context of functional behaviour assessment and Positive Behavioural Supports. Drawing from these studies and the behavioural literature, as well as the authors' clinical experience and research, suggestions regarding early intervention for challenging behaviour with children with Down syndrome are provided.
\end{abstract}

Keywords: applied behaviour analysis, functional behaviour assessment, Positive Behaviour Support, behavioural phenotype, proactive strategies, setting events, antecedent strategies, skill replacement, reinforcement systems, consequence strategies.

Children with Down syndrome have a propensity to engage in behaviours that can be particularly problematic for family members and caregivers, as well as professionals who work with them. Such behaviour, referred to by Doss and Reichle (1991) as challenging behaviour, is defined as that which results "...in self-injury or injury of others, causes damage to the physical environment, interferes with the acquisition of new skills, and/or socially isolates the learner" (p. 215). The presence of challenging behaviour, along with characterisations such as "stubborn," have long been noted in the literature (Gibson, 1978). More recently, parent and teacher ratings indicate that children with Down syndrome show higher rates (than typically developing children) of attention problems, social withdrawal, noncompliance, and compulsions (such as arranging objects and repeating certain actions) (e.g., Coe et al., 1999; Evans \& Gray, 2000) and high rates of self-talk (Glenn \& Cunningham, 2000). Additionally, behaviours associated with anxiety, 
K.M. Feeley and E.A. Jones $•$ Challenging behaviour in children with Down syndrome

depression, and withdrawal, have been noted to increase with age (Dykens \& Kasari, 1997).

There are specific physical characteristics of Down syndrome (e.g., those associated with sleep disorders) (Richdale, Francis, Gavidia-Payne \& Cotton, 2000; Stores, 1993) as well as a higher incidence of illness (Roizen, 1996) that may significantly impact the behavioural repertoires, including increasing the likelihood of challenging behaviour, in children with Down syndrome. Researchers have also demonstrated that challenging behaviour, particularly avoidance behaviour, appears consistently in very young infants with Down syndrome (Wishart, 1993a, 1993b). Specifically, when presented with task demands just slightly above their current level of ability, children with Down syndrome demonstrate a unique pattern of behaviour involving opting out of learning opportunities and misusing social behaviours. It appears that the presence of the extra chromosome associated with Down syndrome affects the likelihood of challenging behaviour beginning in infancy. In turn, these behaviours can have catastrophic effects; interfering with learning in children with Down syndrome, not only at the foundational level during infancy, but throughout life.

These characteristics that impact the behaviour repertoire reflect a unique pattern of strengths and weaknesses evident in individuals with Down syndrome and have been described as a distinct cluster of behaviours termed a behavioural phenotype. Dykens (1995) defined behavioural phenotype as "...the heightened probability or likelihood that people with a given syndrome will exhibit certain behavioural and developmental sequela relative to those without the syndrome" (p. 523). This does not mean that all children with Down syndrome will demonstrate all of the characteristic behaviours; rather, there will be in an increased likelihood.

The early developing avoidance behaviour reported by Wishart and colleagues along with reports of other challenging behaviour is believed to be part of this phenotype in very young children with Down syndrome (Fidler, 2005). Thus, it is of utmost importance to intervene on the behaviours characteristic of this behavioural phenotype early on so that they do not result in pronounced deficits within the child's later development.

Challenging behaviour not only precludes individuals with Down syndrome from learning opportunities within their environment, but also prevents them from accessing more typical educational and community environments as they approach preschool and school age. When placement in a general education or community setting does occur, challenging behaviour is likely to be the cause of removal from these settings. This is particularly unfortunate, as general education settings have been found to lead to more positive outcomes for children with Down syndrome (Buckley, Bird, Sacks \&
Archer, 2002; Cunningham, Glenn, Lorenz, Cuckle \& Shepperdson, 1998). Therefore, interventionists who are likely to encounter behaviour that may be associated with later negative outcomes must be prepared to address such behaviour so that children with Down syndrome benefit from learning opportunities and are less likely to be precluded from general education/community placements.

Fortunately, the methodology of applied behaviour analysis, demonstrated effective across a wide range of populations, with various disabilities, can be utilised to address the unique characteristics of challenging behaviour demonstrated by children with Down syndrome. With thousands of studies demonstrating the positive impact of interventions based on the principles of behaviour analysis on the lives of individuals with disabilities, both researchers and practitioners have long relied on this scientific literature to address the challenging behaviour of individuals with developmental disabilities. Recently, the technology of Positive Behaviour Support (Carr et al., 2002) has emerged as an application of the principles of behaviour analysis to not only address skill repertoires, but also redesign individuals' living environments with the goal of achieving enhanced quality of life and decreases in problem behaviour (Carr et al., 1999).

To date, researchers have not specifically applied the principles of behaviour analysis and positive behaviour support to meet the unique behavioural challenges presented by individuals with Down syndrome. However, in an extensive review of the literature, we identified a small number of studies utilising behavioural assessment strategies, as well as several intervention studies that addressed severe challenging behaviour in individuals with Down syndrome. The focus of these investigations was not on the unique characteristics of individuals with Down syndrome, rather the focus was a particular form of challenging behaviour (e.g., aggression, self-injury) or a particular intervention strategy (e.g., reinforcement) and involved either a sole participant who had Down syndrome or several participants, only one or two of whom had Down syndrome.

In this paper, we briefly describe applied behaviour analysis and its applications in assessing and addressing challenging behaviours prevalent in children with Down syndrome. We then draw upon the existing literature as well as our clinical experience and ongoing research to provide suggestions regarding behaviourally based applications to ameliorate specific challenging behaviours associated with Down syndrome in an effort to intervene as early as possible on this aspect of the behavioural phenotype characteristic of children with Down syndrome. 


\section{Applied behaviour analysis}

Based upon the seminal work of Baer, Wolf and Risley (1968), applied behaviour analysis emphasises interventions addressing socially significant age-appropriate behaviours with immediate importance to the individual using precise measurement of those behaviours in need of improvement. Generalised behaviours, that is, behaviours that are maintained over time, appear in other environments, and extend to other behaviours, are targeted. A functional relationship between changes in behaviour and the intervention being implemented is demonstrated. Interventions, derived from the basic principles of behaviour (e.g., reinforcement, extinction), are described so that they can be easily replicated, and their effectiveness is measured by improvement in the individual's performance.

\section{Functions of challenging behaviour}

It has long been established that challenging behaviour is directly related to environmental variables (e.g., how the behaviour is consequated). From a behaviour analytic perspective, challenging behaviours are maintained because they are positively reinforced (i.e., result in the delivery of a preferred item/activity) and/or are negatively reinforced (i.e., result in the removal of a nonpreferred item/activity). O'Neill, Horner, Albin, Storey and Sprague (1997) described these two major functional categories of behaviour as either to obtain or to escape/ avoid. That is, behaviour may function to obtain consequences such as attention (e.g., from a parent or teacher) and access to objects (e.g., snacks, toys) or activities (e.g., recess, trip to the park). Behaviour may also function to escape/avoid consequences such as attention (e.g., interactions with peers) and objects (e.g., certain foods) or activities (e.g., academic tasks).

In addition to the functions of obtain or escape/avoid, O'Neill et al., (1997) further categorise the functions of challenging behaviours in terms of socially or nonsocially motivated behaviours. Socially motivated behaviours involve those in which the child seeks to escape/avoid or obtain something from another individual in their environment. Behaviours serving a social function in children with developmental disabilities are often related to impairments in communication skills (Carr \& Durand, 1985; Durand \& Carr, 1991; 1992). Nonsocially motivated behaviours involve those in which the child seeks to escape/avoid or obtain internal stimuli (i.e., sensory stimulation) and, thus, do not involve consequences related to another individual. These nonsocially motivated behaviours are often referred to as 'self-stimulatory' behaviours.
The work of Wishart (1993a; 1993b) and Wishart and Duffy (1990) suggests that certain functions of challenging behaviour may be more characteristic of children with Down syndrome and part of the characteristic behavioural phenotype. In particular, both escape and attention seeking functions seem prevalent in Wishart's reports of performance during assessment tasks. Specifically, Wishart and colleagues (Pitcairn \& Wishart, 1994; Wishart, 1986; Wishart \& Duffy) report avoidance behaviours ranging from disruptive tantrum behaviours (e.g., sweeping test items off the table) to charming or 'cute' behaviours (e.g., clapping, blowing raspberries) that might distract the evaluator during task demands. The overlapping attention seeking function of such task avoidance behaviours was also noted by Kasari and Freeman (2001) who confirmed the higher frequency of these 'charming' behaviours in older children with Down syndrome (6-10 years). In fact, in their study, children with Down syndrome engaged in higher rates of looking to the experimenter during a task situation that may have been related to the significantly longer latency to start and complete tasks, when compared to typically developing children and children with mental retardation not related to Down syndrome.

As a result of these findings, it seems that both escape and attention seeking behaviours may be particularly prevalent in children with Down syndrome. To determine the extent to which an individual child possesses these specific characteristics (increased likelihood of engaging in escape/avoid or attention motivated problem behaviour) of the behavioural phenotype, interventionists can conduct a functional behaviour assessment. Not only will this enable interventionists to explore this aspect of the behavioural phenotype, but specific antecedents and consequences associated with the challenging behaviour can be determined.

\section{Functional behaviour assessment}

While certain functions (e.g., escape, obtain attention) may be associated with Down syndrome, challenging behaviour can serve a variety of functions within and across individual children. Therefore, the foundation of addressing challenging behaviour is determining the function a specific challenging behaviour serves for a particular child (i.e., to obtain or escape/avoid; socially or non-socially motivated). This is accomplished via the functional behaviour assessment process in which the relationship between events in a person's environment and the occurrence of challenging behaviour is determined in an effort to identify factors maintaining that behaviour. (The reader is referred to O'Neill et al.'s [1997] 
K.M. Feeley and E.A. Jones $\cdot$ Challenging behaviour in children with Down syndrome

practical handbook for a detailed discussion of functional behaviour assessment procedures.)

\section{Interview}

The first step in the functional assessment process consists of an interview to identify the behaviour of concern; related environmental/medical factors; and when/where/ with whom and during which activities the behaviour occurs most/least. The goal is to identify factors that are related to the occurrence of challenging behaviour.

In the past, when addressing challenging behaviour, the field of applied behaviour analysis concentrated on the immediate antecedents and consequences. However, several behaviourists have recognised that events occurring more distally in time or not directly related to the immediate antecedents or consequences affect the likelihood of challenging behaviour (Michael, 1982; 2000; Wahler \& Fox, 1981). Such variables have been referred to as motivating operations (Michael, 2000) as well as setting events (Wahler \& Fox, 1981). Specifically, motivating operations refer to antecedents that affect an individual's behaviour by changing the value (increasing or decreasing) of a consequence (reinforcer or punisher) which, in turn, changes the likelihood the individual will engage in a certain behaviour (either increasing or decreasing the likelihood). For example, a child may be motivated to follow the directions (immediate antecedent) of his teacher because doing so results in a pleasant interaction (i.e., the teacher smiles and praises the child; reinforcing consequence). However, if the child has a cold, the reinforcing value of the smile and praise may be significantly decreased, thus, decreasing the likelihood the child will engage in compliant behaviour in response to the teacher's requests. In this situation, the cold is a motivating operation.

The term motivating operation has been used to describe the effect a specific event has on the quality of a future consequence (e.g., reinforcer) and, thus, the likelihood of the target behaviour occurring. Within the Positive Behaviour Support literature, the term setting event is widely used to represent the phenomena described (Horner, Vaughn, Day \& Ard, 1996). Several studies have been conducted describing a relationship between different setting events (e.g., illness, sleep problems) in the lives of individuals with developmental disabilities and a propensity to engage in challenging behaviour (e.g., Dadson \& Horner, 1993; McGill, Teer, Rye \& Hughes, 2005).

We suggest that the propensity of individuals with Down syndrome to engage in challenging behaviour is directly related to several motivating operations (or setting events) that are inherently related to the presence of Down syndrome. For example, Stores (1993) found more frequent sleep problems, including restless sleep, waking more than once per night, and waking prior to 5:00 am, in children with Down syndrome compared to typically developing children. The higher incidence of sleep problems appears to be related to several physical features (specifically, upper airway obstruction due in part to relatively small mouths and airway passages, enlarged tonsils, and obesity) (Stores \& Stores, 1996). These sleep problems were also associated with daytime problem behaviour: specifically, irritability, hyperactivity, and stereotypies (Richdale et al., 2000; Stores, 1993). Thus, sleep disorders may be one motivating operation that affects the likelihood of challenging behaviour in children with Down syndrome.

There is also a high incidence of illness in children with Down syndrome (e.g., recurrent ear infections, gastrointestinal disorders, skin conditions) (Roizen, 1996). The onset of an illness, its presence, as well as the ending stages, may be motivating operations affecting the behaviour of children with Down syndrome, as is often the case with typically developing children. As the frequency and severity of these illnesses is increased in individuals with Down syndrome, the incidence of challenging behaviour is likely to be increased as well.

It is during the interview process that environmental events including setting events/motivating operations, antecedents, and consequences, as well as target behaviours are identified. It is here that interventionists should closely examine the extent to which specific motivating operations (or setting events) associated with Down syndrome affect the individual's likelihood of engaging in challenging behaviour. Just as the function of behaviour is likely to vary across individuals, the specific antecedents and consequences as well as the presence of motivating operations (or setting events) are likely to be unique to each child with Down syndrome and require careful assessment to determine which are relevant for a given child.

\section{Direct observation}

The second component of the functional behaviour assessment process consists of direct observation of the individual and documentation of events that occur prior to and following the challenging behaviour. One example is an antecedent-behaviour-consequence $(\mathrm{ABC})$ analysis, in which antecedents and consequences are documented as they occur in the natural environment. The child is observed during his/her daily routine and the occurrence of challenging behaviours, events that precede the specific behaviour (antecedents), and events that follow the specific behaviour (consequences) are documented. Analysis of the pattern of antecedents and consequences results in a hypothesised function of the challenging behaviour. 
See Table 1 for an ABC data sheet with guidelines regarding information that should be included and Table 2 for an example ABC data sheet with sample behaviours.

\section{Functional analysis}

Often, the function of a particular challenging behaviour for a child can be identified through the interview and direct observation process. However, a more systematic approach may be necessary to confirm observation findings and/or determine the function, if it has not been clearly identified. Functional analysis consists of the systematic manipulation of controlling variables to demonstrate the function of the behaviour (the reader is referred to O'Neill et al., 1997 as well as Iwata, Dorsey, Slifer, Bauman \& Richman, 1982 for explicit procedures). Functional analysis involves measuring challenging behaviour as a series of conditions are introduced. Consequence conditions include situations in which: attention is delivered contingent upon the occurrence of challenging behaviour (attention condition); demands are removed contingent upon the occurrence of challenging behaviour (demand condition); tangibles are delivered contingent upon the occurrence of challenging behaviour (tangible condition); the child is left alone and no consequences are delivered by others (alone condition); and a condition involving noncontingent delivery of preferred items and attention (free play or control condition). Antecedent conditions can also be manipulated, such as task difficulty or attention provided while engaged in the task. The conditions in which the challenging behaviour occurs are indicative of the factor(s) occasioning and/or maintaining the behaviour. For example, if higher rates of challenging behaviour occur within the demand condition than within the other conditions, escape would appear to be the function of the challenging behaviour.

Once the functional behaviour assessment process is complete, and the function of the challenging behaviour identified, intervention procedures can be developed that specifically address the challenging behaviour and the function it serves for that individual. Interventionists should draw from the large number of empirically validated studies demonstrating the facilitative effects of behaviour analytic procedures.

\section{Intervention}

An effective means of addressing challenging behaviour, Positive Behaviour Support (Carr et al., 2002), is rooted in behaviour analytic strategies. Positive Behaviour Support consists of strategies addressing multiple variables influencing the occurrence of challenging behaviour. When utilised at an individual level, Positive Behaviour Support interventions consist of the development of a four component approach which includes strategies to address motivating operations/setting events and immediate antecedents, interventions to teach replacement skills (e.g., communication, academic, social), and the development of appropriate consequence strategies (e.g., reinforcement strategies) as outlined in Figure 1. To illustrate behavioural applications within this four component framework, we will provide a brief description of a select few studies implemented with children with Down syndrome, followed by additional suggestions for interventions based upon the research literature and our clinical experience and research. The studies 


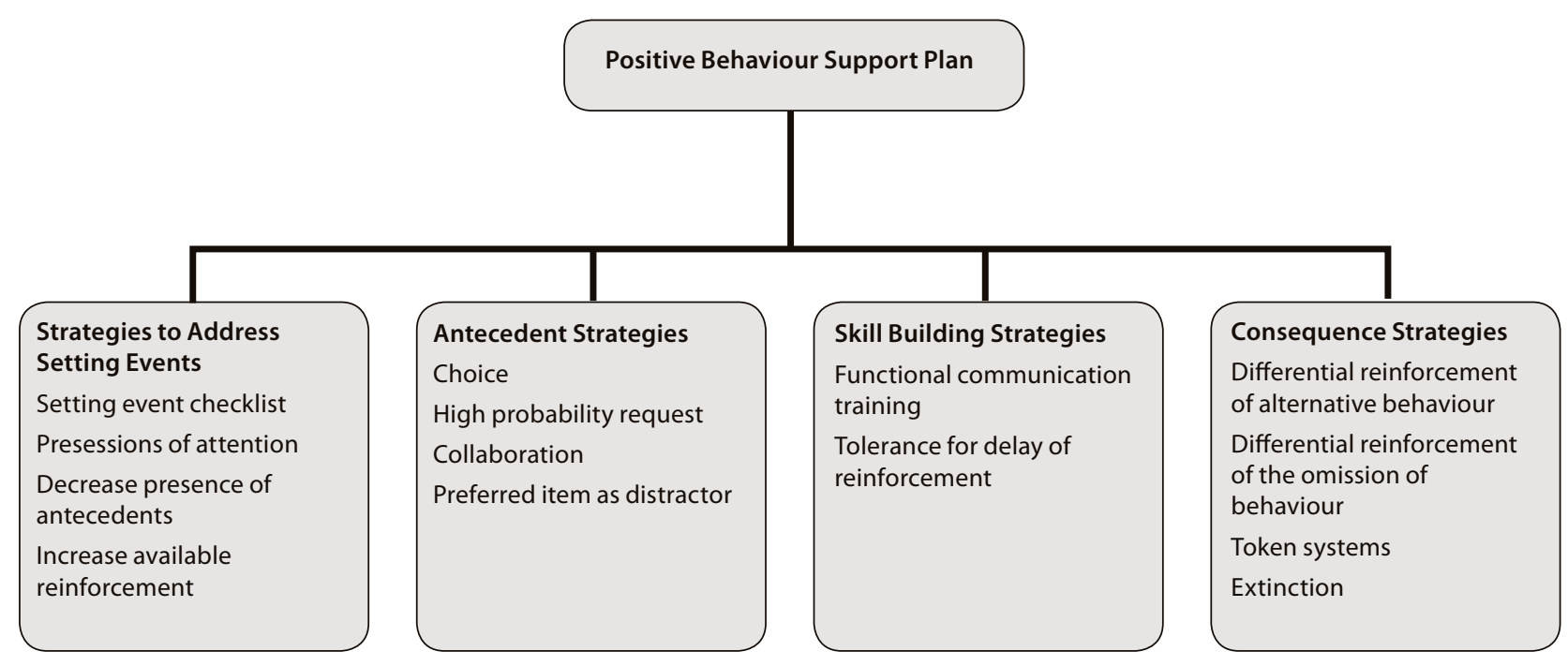

Figure 1: Components of a Positive Behaviour Support Plan with example interventions.

utilising behavioural strategies with individuals with Down syndrome we will discuss are outlined in Table 3.

\section{Addressing setting events (motivating operations)}

Because the term setting event is used in the Positive Behaviour Support literature, we have chosen to use it in our discussion of intervention strategies. One setting event that we hypothesise may be specifically associated with Down syndrome is the tendency toward an increased desire to escape/avoid demands and to obtain attention as suggested by Wishart's research (1993a, 1993b). McComas, Thompson and Johnson (2003) utilised a setting event intervention strategy consisting of presessions during which attention was provided. Several children participated in this study, two of whom had Down syndrome (11 and 12 year old boys). In one condition, attention was delivered noncontingently (i.e., regardless of the child's behaviour) during the $10 \mathrm{~min}$ utes prior to engagement in tasks likely to elicit challenging behaviours (i.e., during presessions). In the second condition, students were ignored during the 10 minute presessions. Although, the presession condition in which attention was provided had no effect on the challenging behaviour of the child who was escape motivated, the child who was attention motivated engaged in challenging behaviour during subsequent tasks almost exclusively when no attention was delivered during the presessions.

McComas et al.'s (2003) study demonstrated the effectiveness of an intervention procedure to specifically address a setting event, in this case, the increased desire for attention. It is important to note, attention served as a reinforcer in the target situation for only one of the two children with Down syndrome (as confirmed by the functional assessment process), while the challenging behaviour of the other child served to escape. Thus, although there is an increased likelihood of some setting events in children with Down syndrome, not all may be pertinent to all children with Down syndrome. Additionally, once the functional assessment process has been completed (taking into account setting events), interventionists should select intervention strategies that directly correspond to the findings. For example, as illustrated by McComas et al., presession attention did not affect individuals who engage in challenging behaviour serving functions other than to obtain attention.

Other setting events, such as sleep disorders and illness, that warrant attention specifically in children with Down syndrome, may be addressed by developing a mechanism for caregivers to share with school personnel when a child has experienced a particular setting event. Checklists can be designed to specifically note setting events influencing the child's challenging behaviour. Alternatively, setting events can be reported via a note sent to school or a telephone call. School personnel can then consider several interventions designed to ameliorate the effects of the specific setting event (e.g., Dadson \& Horner; 1993; Horner et al., 1996). For example, a child's illness may increase the likelihood that he/ she engages in self stimulatory behaviour (e.g., repetitive hand movements). In this case, the child might be given the opportunity to access materials that would function as a replacement response (e.g., holding onto a small textured toy stored within the front pocket of a sweatshirt). Another child who experiences trouble sleeping might be more likely to desire to escape demands. In this case, the child may be given an opportunity to rest at some point during the day, or school staff might consider reducing their demands (e.g., requesting fewer academic tasks) on days following disrupted sleep. The effects of the setting 


\section{Table 3. Studies examining the use of behavioural interventions to address challenging behaviour in children with Down syndrome}

\begin{tabular}{|c|c|c|c|c|}
\hline $\begin{array}{l}\text { Author/ } \\
\text { Year }\end{array}$ & $\begin{array}{l}\text { Subject/Setting } \\
\text { Description }\end{array}$ & $\begin{array}{l}\text { Target Behaviour and } \\
\text { Function }\end{array}$ & Independent Variable & Results \\
\hline $\begin{array}{l}\text { Cole \& } \\
\text { Levinson } \\
(2002)\end{array}$ & $\begin{array}{l}7 \text { year old boy with } \\
\text { Down syndrome, PDD, } \\
\text { and ADD attending } \\
\text { a school for students } \\
\text { with emotional/ } \\
\text { behavioural disorders }\end{array}$ & $\begin{array}{l}\text { Throwing/destroying items, } \\
\text { hitting, and dropping to } \\
\text { the floor) } \\
\text { Function: No functional } \\
\text { assessment was conducted }\end{array}$ & $\begin{array}{l}\text { Choice versus no } \\
\text { choice embedded } \\
\text { within verbal prompts } \\
\text { delivered during } \\
\text { instruction of daily } \\
\text { routine }\end{array}$ & $\begin{array}{l}\text { Challenging behaviour decreased } \\
\text { from a range of } 14.3 \% \text { to } 81.8 \% \text { in the } \\
\text { no choice condition to } 8.3 \% \text { in the } \\
\text { choice condition, with an increase in } \\
\text { independent task performance }\end{array}$ \\
\hline $\begin{array}{l}\text { Davis, } \\
\text { Brady, } \\
\text { Williams \& } \\
\text { Hamilton } \\
\text { (1992) }\end{array}$ & $\begin{array}{l}7 \text { year old boy with } \\
\text { Down syndrome, } \\
\text { enrolled in a life } \\
\text { skills program on an } \\
\text { elementary school } \\
\text { campus }\end{array}$ & $\begin{array}{l}\text { Noncompliance, kicking, } \\
\text { screaming, spitting, } \\
\text { stereotypic behaviour, } \\
\text { emptying cabinets/drawers } \\
\text { Function: No functional } \\
\text { assessment was conducted }\end{array}$ & $\begin{array}{l}\text { The delivery of three } \\
\text { to five high-probability } \\
\text { requests, each followed } \\
\text { by the delivery of verbal } \\
\text { or gestural (thumbs up) } \\
\text { praise }\end{array}$ & $\begin{array}{l}\text { Compliance increased from a } \\
\text { mean of } 6.7 \% \text { during baseline to } \\
100 \% \text { following intervention, with } \\
\text { performance generalised to other } \\
\text { adults and was maintained during } \\
\text { follow up probes }\end{array}$ \\
\hline $\begin{array}{l}\text { Hall, } \\
\text { Neuharth- } \\
\text { Pritchett } \\
\text { \& Belfiore } \\
\text { (1997) }\end{array}$ & $\begin{array}{l}9 \text { year old boy with } \\
\text { Down syndrome } \\
\text { in a self contained } \\
\text { classroom with } \\
\text { inclusive opportunities }\end{array}$ & $\begin{array}{l}\text { Aggression: hitting, } \\
\text { destroying and throwing } \\
\text { materials } \\
\text { Function: both escape and } \\
\text { attention }\end{array}$ & $\begin{array}{l}\text { Instruction of } \\
\text { communicative } \\
\text { replacement of raising } \\
\text { hand and saying "done" }\end{array}$ & $\begin{array}{l}\text { Aggressive/destructive behaviour } \\
\text { decreased from } 11 \% \text { (of the } 10 \\
\text { second intervals within a } 45 \text { minute } \\
\text { session) in baseline to } 2 \% \text { during } \\
\text { intervention } \\
\text { Performance generalised from his } \\
\text { special education classroom to a } \\
\text { general education classroom }\end{array}$ \\
\hline $\begin{array}{l}\text { McComas, } \\
\text { Thompson } \\
\text { \& Johnson } \\
(2003)\end{array}$ & $\begin{array}{l}\text { Two boys with Down } \\
\text { syndrome enrolled } \\
\text { in special education } \\
\text { classes within a public } \\
\text { school: } \\
\text { Dan, } 11 \text { years old } \\
\text { Ari, } 12 \text { years old }\end{array}$ & $\begin{array}{l}\text { Dan: throwing materials, } \\
\text { hitting, and spitting } \\
\text { Function: attention seeking } \\
\text { Ari: hitting, pinching, } \\
\text { kicking, throwing items } \\
\text { Function: escape }\end{array}$ & $\begin{array}{l}\text { Noncontingent } \\
\text { attention versus no } \\
\text { attention during } 10 \\
\text { minute presessions } \\
\text { prior to engaging in } \\
\text { tasks likely to elicit } \\
\text { challenging behaviour }\end{array}$ & $\begin{array}{l}\text { Challenging behaviour decreased for } \\
\text { Dan (who was attention motivated) } \\
\text { when attention presessions were } \\
\text { provided } \\
\text { Challenging behaviour did not } \\
\text { change for Ari (who was escape } \\
\text { motivated) }\end{array}$ \\
\hline $\begin{array}{l}\text { Repp \& } \\
\text { Karsh } \\
(1994)\end{array}$ & $\begin{array}{l}9 \text { year old girl with } \\
\text { Down syndrome } \\
\text { placed in a segregated } \\
\text { school }\end{array}$ & $\begin{array}{l}\text { Tantrums (crying, falling } \\
\text { to floor, kicking, hitting, } \\
\text { throwing objects, and } \\
\text { grabbing) and finger } \\
\text { stereotypies (finger } \\
\text { flexions) } \\
\text { Function: attention }\end{array}$ & $\begin{array}{l}\text { Extinction, differential } \\
\text { reinforcement of } \\
\text { alternative behaviour, } \\
\text { and increased } \\
\text { opportunities to engage } \\
\text { in social interactions }\end{array}$ & $\begin{array}{l}\text { Challenging behaviour decreased } \\
\text { from } 41 \% \text { of the day in baseline to an } \\
\text { average of } 4 \% \text { during intervention } \\
\text { Maintenance observed at one year } \\
\text { follow-up }\end{array}$ \\
\hline
\end{tabular}

events may also be ameliorated through the delivery of higher rates and/or higher quality of reinforcement. This reinforcement should be delivered before the child is likely to engage in the challenging behaviour (Marcus \& Vollmer, 1996). For example, a child can be greeted at the bus with high rates of quality attention and, therefore, may be less likely to engage in attention motivated challenging behaviour upon entering the classroom.

Strategies to address setting events can have substantial effects on the likelihood of challenging behaviour. However, in many instances, it may also be necessary to consider interventions that target immediate antecedents.

\section{Antecedent based strategies}

Intervention strategies targeting stimuli that occur just prior to the child engaging in challenging behaviour are termed antecedent based strategies (Kern, Choutka \& Sokol, 2002). These strategies aim to prevent the occur- rence of challenging behaviour by altering the antecedent situations associated with it (e.g., decreasing the aversiveness of the antecedent stimuli). Thus, these strategies are implemented proactively, that is, prior to the point at which the challenging behaviour is likely to occur (identified via the functional assessment process). Four strategies may be particularly relevant to decrease the escape and/or attention motivated challenging behaviours often seen in children with Down syndrome: choices, high probability request sequence, collaboration, and preferred item as distractor.

Offering choices (e.g., of tasks, materials, locations, etc.) is a strategy that has been effectively used in a number of studies to decrease challenging behaviour (e.g., Bambara, Koger, Katze \& Davenport, 1995; Dunlap, et al., 1994; Dyer, Dunlap \& Winterling, 1990). In one application with a 7 year old boy with Down syndrome, Cole and Levinson (2002) demonstrated the effectiveness of embedding choices within the daily routine of hand washing, a situation during which the boy was likely to engage in 
K.M. Feeley and E.A. Jones $\cdot$ Challenging behaviour in children with Down syndrome

challenging behaviour (e.g., throwing/destroying items, hitting, and dropping to the floor). Rather than delivering a directive regarding how to complete a step within the task (e.g., "Rub your hands"), the child was offered choices regarding how the step could be completed (e.g., "Do you want to rub them together quickly or slowly?"). Challenging behaviour decreased while independent task participation increased. Thus, while presenting tasks that trigger challenging behaviour, choices can be offered with respect to a variety of aspects, such as location (e.g., "You can work at your desk or at the group table"), peers ("Would you like to walk with John or Mary?"), or materials (e.g., "You can use your pencil or my blue pen") to decrease escape motivated challenging behaviours.

Another antecedent strategy, high probability request sequence, involves the delivery of a series of requests to which the child is highly like to comply (a high probability request) each of which is followed by the delivery of reinforcers, then a request to which the child is not likely to comply, that is, a low probability request (the one that triggers the challenging behaviour) is delivered. For example, Davis, Brady, Williams and Hamilton (1992) successfully utilised high probability request sequence to increase compliance and decrease challenging behaviour (screaming, hitting, kicking, spitting) in a 7 year old boy with Down syndrome. Behaviour change generalised across classroom staff and was maintained during a series of 4 weekly follow up probes. High probability request sequences have not only been effective in decreasing challenging behaviours (Horner, Day, Sprague, O’Brien \& Heathfield, 1991; Mace \& Belfiore, 1990), but also increasing compliance (Mace et al., 1988; Singer, Singer \& Horner, 1987), particularly during transitions (Davis, Reichle \& Southard, 2000), as well as increasing social interactions (Davis, Brady, McEvoy \& Williams, 1994; Davis \& Reichle, 1996) and communicative behaviours (Davis, Reichle \& Johnston, 1998). This strategy may be particularly effective with a child who is not only escape/ avoid motivated, but also attention motivated, because, inherent in the high probability request sequence, each compliant response results in social reinforcement (e.g., praise).

A third antecedent strategy that may be particularly effective for children with Down syndrome who not only desire to escape/avoid a task, but also obtain attention, is an offer of collaboration (Davis, McEvoy \& Riechle, 2005). This entails sharing the responsibility of the task with the child. For example, during a worksheet task, the interventionist tells the child, "You do the first five items and I'll do the last five." Over time, the amount of assistance provided by the interventionist can be systematically faded (e.g., "You do the first six, and I'll do the last four") until the child is performing independently.

Lastly, preferred item as a distractor (Davis et al., 2000) involves presenting a child with a preferred item to dis- tract them from the aversiveness of the task that triggers challenging behaviour. The preferred item is systematically presented prior to, or simultaneous with, the request that is likely to occasion the challenging behaviour. For example, a child can be given a favourite toy and then requested to take a walk to another instructional area. Alternatively, the interventionist may embed the preferred item (e.g., whistle) into the request (e.g., "Can you hold the whistle while we walk in from recess?").

For antecedent strategies to be effective, it is essential for interventionists to be fluent in their use, paying particular attention to implementing the strategies prior to presenting the antecedents that are associated with the behaviour. While setting event and antecedent based intervention strategies serve to proactively decrease the likelihood that challenging behaviour will occur, it is important to recognise the function the challenging behaviour serves for a particular child and teach replacement skills for the child to use to obtain what they want through more appropriate means.

\section{Replacement skills}

Many individuals with Down syndrome can benefit from instruction in specific skills (e.g., communication, social, academic, etc.) that function to replace challenging behaviour with a more appropriate means of obtaining reinforcers. One type of skill building strategy, functional communication training, involves identifying and teaching a more appropriate communicative response serving the same function as the challenging behaviour (Carr et al., 1994).

Several researchers (e.g., Brooks, Todd, Tofflemoyer \& Horner, 2003; Hetzroni \& Roth, 2003) have implemented functional communication training with children with Down syndrome. For example, Hall, Neuharth-Pritchet and Belfiore (1997) determined that the aggressive and destructive behaviours of a 9 year old boy with Down syndrome served the function of both escape (the wait) and attention when he was required to wait after completing a task. He was taught to indicate when he was finished by raising his hand and saying "done" which resulted in the delivery of a brief, in-seat academic activity. Acquisition of this replacement response resulted in a decrease in aggressive/destructive behaviours that generalised from his special education classroom to a general education classroom.

As the speech and language skills of individuals with Down syndrome are specifically impaired, their ability to communicate desires is likely to be compromised and, thus, related to the occurrence of challenging behaviour. Based on the extensive literature examining the effectiveness of functional communication training (e.g., Carr \& Durand, 1985; Durand \& Carr, 1991; 1992), com- 
municative replacement strategies can be used to address a variety of communicative functions. For example, a child who desires to escape circle time activities can be taught to raise his/her hand to request to leave the area. For a child who desires attention, he/she can be taught to tap an adult's shoulder to request attention (e.g., to read a book). A child who tends to tantrum in the presence of desired objects can be taught to appropriately request the desired object (e.g., point to communication symbols "want" "[item]").

When teaching a child to communicate his/her desires instead of engaging in challenging behaviour, it is crucial to reinforce appropriate communicative behaviours with immediate access to what the child desires (e.g., a break for a child who is escape motivated, attention for the child who is attention motivated). Once the communicative replacement response is acquired, it is possible to systematically teach the child to wait longer periods of time before the child can access what they desire. This intervention is referred to as teaching tolerance for delay of reinforcement (Carr et al., 1994). For example, once the child reliably uses the replacement communication skill (e.g., raising his/her hand), when the child makes the appropriate request, increasing amounts of time can be inserted before delivery of the reinforcer (e.g., tell the child "Just one minute.").

Replacement skills are particularly important as they provide the child with a communicative response that can be used across multiple situations to more appropriately obtain desirable outcomes. It is equally important for interventionists to also implement effective consequence strategies for both appropriate and inappropriate behaviour.

\section{Consequence strategies}

Effective interventions addressing challenging behaviour typically include reinforcement systems for appropriate behaviour as well as consequences for inappropriate behaviour. For example, Repp and Karsh (1994) conducted a study with two students, one of whom was a 9 year old girl with Down syndrome whose challenging behaviours consisted of tantrums (crying, falling to floor, kicking, hitting, throwing objects, and grabbing) and finger stereotypies (finger flexions) that had resulted in her removal from an integrated educational setting. Direct observation during baseline indicated that, although she engaged in tantrums within demand situations, she was consistently consequated with attention rather than withdrawal of demands. Intervention consisted of placing the tantrum behaviour on extinction (in this case, no longer providing attention) as well as increasing the rate of reinforcement for task engagement (differential reinforcement of alternative behaviour (DRA), that is, reinforcement of the alternative behaviour of task engagement), along with providing increased opportunities to engage in social interactions. This intervention package resulted in a decrease in challenging behaviour which maintained at one year follow-up. Thus, a combination of consequence strategies for both the challenging behaviour (i.e., extinction) and more appropriate behaviour (i.e., DRA) were important components of effective intervention.

Repp and Karsh's (1994) study illustrates two points with respect to consequence strategies. First, their findings that challenging behaviour, in the presence of demands, may actually serve the purpose of accessing attention, are particularly relevant in light of Wishart's work (Wishart \& Duffy, 1990; Pitcairn \& Wishart, 1994) demonstrating the propensity of children with Down syndrome to engage in what appear to be escape motivated challenging behaviours. They do so, however, in a very social manner (e.g., engaging in party tricks) which often results in not only escaping/avoiding a task, but also obtaining attention. In many instances, the exact consequences maintaining challenging behaviour may be unclear, making intervention selection difficult. However, systematic implementation of functional assessment procedures in conjunction with carefully chosen interventions that specifically address the escape and attention motivated functions of behaviour can lead to significant changes in the behavioural repertoires of children with Down syndrome.

Second, Repp and Karsh's (1994) study illustrates the use of reinforcement procedures (i.e., DRA) to decrease a challenging behaviour. Another reinforcement procedure, differential reinforcement of the omission of behaviour (DRO), is particularly effective with stereotypical behaviours (e.g., Repp, Deitz \& Speir, 1974). DRO involves delivering reinforcement following an interval of time in which the challenging behaviour did not occur. We have used this procedure with several children with Down syndrome to successfully decrease self-stimulatory behaviours (e.g., mouthing objects, tongue clicking, and lip licking). In all cases, functional assessment indicated the behaviours were non-socially motivated. Each child was initially reinforced on a dense schedule (e.g., every 30 seconds). The time interval was then quickly increased (to $1,3,5$, and 10 minute intervals) to the point at which, for each of the children, the behaviour completely subsided and continued reinforcement specifically for the absence of that self-stimulatory behaviour was no longer necessary.

Two criticisms of DRO procedures are the intervention does not leave the individual with a specific skill, rather it only decreases the target behaviour and in some instances, the function of the challenging behaviour is not honoured (i.e., reinforcement is delivered based on the omission of the behaviour with no specific functional 
K.M. Feeley and E.A. Jones $\cdot$ Challenging behaviour in children with Down syndrome

equivalent response being taught). Thus, many interventionists prefer to implement differential reinforcement of alterative behaviours (DRA), such as that used by Repp and Karsh (1994), in which an alternative response is consistently reinforced. As another example, consider a child who has a tendency to place objects in his mouth to get attention. Appropriate responses (e.g., play behaviours with the objects) can be selected to systematically reinforce. If not readily within the child's repertoire, the child can be prompted to perform the behaviour and then immediately provided with reinforcers. Thus, the challenging behaviour (mouthing objects) can be replaced with an appropriate play behaviour. In instances in which the alternative response is communicative in nature, such as within functional communication training, differential reinforcement (DRA) is in effect.

For socially motivated behaviours, such differential reinforcement procedures are often paired with extinction to increase their effectiveness. Extinction involves no longer delivering reinforcement following the occurrence of challenging behaviour. Using the previous example, the target behaviour (i.e., mouthing objects) would no longer be reinforced, thus, no attention would be delivered following its occurrence (i.e., extinction). This would be paired with high quality reinforcement (i.e., attention would be delivered following appropriate play behaviours) delivered following the alternative behaviour. The function of challenging behaviour must be considered, not only in consequating challenging behaviour, but also in the choice of reinforcers to increase appropriate behaviour. In the previous example, appropriate play behaviour resulted in attention. As another example, a student who is escape motivated can be reinforced for appropriate task completion with the removal of one or several demands.

Reinforcement systems such as token economies, in which tokens (e.g., stickers, check marks) are delivered for appropriate behaviour and then cashed in at some later point for backup reinforcers (e.g., toys, food), can also be used to reinforce appropriate behaviour. Such token systems exist in many classrooms, but often need to be individualised to meet the unique needs of a particular child with Down syndrome. Token systems can even be used by caregivers within the home with very young children with Down syndrome and may be particularly relevant with escape behaviour. For example, we have used token systems consisting of cartoon character tokens (e.g., Barney $^{\mathrm{TM}}$, Blues Clues ${ }^{\mathrm{TM}}$ ) with children as young as two years of age to sustain performance during tasks where escape behaviour was typically displayed.

With the development of empirically demonstrated behavioural intervention strategies, the systematic use of consequence strategies designed to decrease behaviour (i.e., the use of punishment procedures) is likely unnecessary. The use of positive interventions has become so widespread that private and public policy statements specifically call for their use prior to consideration of reactive or punishment based procedures. For example, in the United States, federal education legislation (Individuals with Disabilities Education Improvement Act of 2004) specifically notes "In the case of a child whose behavior impedes the child's learning or that of others, consider the uses of proactive behavioral interventions and supports..." (Sec. 614). However, when positive approaches have been systematically applied with little success, the use of reactive procedures implemented to decrease the future likelihood of challenging behaviours may be warranted. For example, consider a child who destroys materials to escape/avoid academic demands. A multicomponent intervention may consist of giving the child a choice of academic activities, the use of a preferred item as a distractor (i.e., "You can use your markers to fill in these questions."), as well as teaching the child to request assistance when the academic task becomes difficult (functional communication training). When the appropriate behaviour(s) occur, the child is immediately reinforced (DRA). However, in the event the target behaviour does occur, that is, the child destroys the materials, interventionists might consider a consequence procedure that is likely to decrease the future occurrence of the behaviour, such as the removal of a privilege (e.g., no recess) or an added chore (e.g., cleaning the dry erase board). In these instances, it is of utmost importance for intervention teams (including caregivers) to make informed decisions, in addition to acquiring consent from all necessary parties and monitoring intervention for desired effectiveness (Cooper, Heward \& Heron, 1987).

\section{Summary}

As the four component approach of positive behaviour support has effectively addressed challenging behaviour in individuals with various developmental disabilities across the age span, it is also likely to effectively meet the needs of children with Down syndrome who engage in challenging behaviours. Positive behaviour support interventions can be used to systematically address characteristics specific to Down syndrome (e.g., increased likelihood of engaging in avoidant and/or attention motivated behaviour) as well as events that occur on an individualised basis. Additionally, as interventionists become versed in the functional assessment process and proactive interventions, they will find themselves naturally implementing many of these strategies, likely resulting in an overall decrease in challenging behaviours emitted by the children with Down syndrome with whom they work. In turn, increasing the child's likelihood of success in inclusive educational and community environments. 


\section{Future applications}

Recent research suggests that the presence of escape and attention motivated challenging behaviour may be part of the behavioural phenotype (Dykens, 1995; Fidler, 2005) that characterises Down syndrome. That is, the disability itself is characterised by a pattern of strengths and weaknesses that increase the likelihood of valuing certain consequences (i.e., escape and attention). McGill (1999) presented the idea that disabilities may function as motivating operations in his discussion of the decrease in the reinforcing value of attention in individuals with autism and the increase in the reinforcing value of food in individuals with Prader-Willi. Although not specifically mentioned by McGill, the work of Wishart and colleagues (Wishart, 1993a; 1993b; Pitcairn \& Wishart, 1994; Wishart \& Duffy, 1990), as well as the cluster of behaviours termed a behavioural phenotype, suggest Down syndrome should be included in the disabilities identified by McGill as motivating operations.

The presence of these challenging behaviours, even within the first year of life in children with Down syndrome, effectively reduces the child's learning interactions with his/her environment. As part of the behavioural phenotype characteristic of Down syndrome, we are challenged to develop strategies to ameliorate these tendencies at a very young age (Fidler, 2005), by first identifying the specific behaviours in which a child engages and then teaching caregivers to respond in such a way that these behaviours are not systematically reinforced (Gerenser, personal communication, June 6, 2004). For example, caregivers often make simple requests of a child that are followed by avoidance behaviour (e.g., turning away). These avoidance behaviours are likely to result in some initial persistence on the part of the caregiver, but, in the face of further child resistance, caregivers may 'give up' and discontinue the request. In these situations, the child, who did not want to comply with the request, is ultimately reinforced; that is, avoidance (e.g., turning away) to respond results in the removal of the demand. Alternatively, caregivers can be taught to follow through with even simple requests. Therefore, when making a request, if the child does not respond, he/she is prompted to do so. Once the response occurs, even if prompted, reinforcement is immediately delivered. This results in teaching the child, from an early age, the benefits of following simple instructions and possibly curtailing a pervasive pattern of opting out as identified by Wishart (1993a, 1993b).

Another way to address escape behaviour in young children with Down syndrome, especially in the presence of slightly more difficult tasks, may be to teach caregivers to manipulate items in the child's environment to make specific tasks less difficult. For example, if the child is having difficulty accessing toys in his environment, the parent might position toys so they are in reach, thus, pulling the toy closer can be more easily accomplished. Caregivers who are well versed in prompting strategies (e.g., the use of physical guidance or positioning of objects to enhance performance) as well as shaping procedures (i.e., reinforcing closer and closer approximations to the target response) can be advised to implement such strategies to enhance their child's performance with a given task. By using prompting and shaping procedures, adults are setting up the situation to provide the young child with Down syndrome with more successful opportunities and then very gradually leading to more difficult tasks. This is one application of errorless learning techniques which, as suggested by Fidler (2005), may result in children with Down syndrome persisting in tasks during which they might otherwise demonstrate escape behaviour.

With respect to the attention seeking functions of challenging behaviour, our clinical experience suggests that, during the toddler and preschool years, attention motivated behaviours are present and particularly interfering. Consider, for example, getting into a forbidden area within the home (e.g., brick fire place, steep stair case, bay window), a common behaviour in toddlers. Many caregivers might instinctively go to the child and remove him/her from the area, but, in doing so, inadvertently deliver attention in the form of verbal feedback (e.g., "No, no honey, that can be dangerous.") as well as physical contact (e.g., once the parent has the child in his/her arms, hugs and kisses are naturally delivered). Because of the positive interaction that ultimately takes place, the child may learn that an effective way to get attention is to move toward the forbidden area. Alternatively, caregivers can systematically respond in a way that is not reinforcing to the child (e.g., silently go to the child without providing eye contact and remove the child from the forbidden area) while at the same time responding in a very reinforcing manner when the child is playing in an acceptable location (e.g., while sitting on the floor with their toys).

Given the early presence of these challenging behaviours, it is essential for professionals to involve caregivers during the development and implementation of interventions so that caregivers can effectively intervene throughout the day and across multiple environments. Professionals should be skilled at imparting intervention techniques to caregivers so they can comfortably implement interventions during ongoing interactions with their young child with Down syndrome. 


\section{Conclusion}

Interventionists versed in behavioural assessment and intervention strategies are likely to have the tools necessary to address the range (in form and function) of behaviours of children with Down syndrome that have, in the past, precluded them from learning opportunities as well as inclusive placements. Although the interventions have not been considered in relation to the work of Dykens (1995) on the existence of a 'behavioural phenotype', the functional assessment process, in conjunction with interventions adhering to sound behaviour analytic principles, appear to be a perfect match for the prevention and amelioration of challenging behaviour in individuals with Down syndrome, particularly early in life when a pattern of challenging behaviour seems to first emerge.

\section{Correspondence}

Dr. Kathleen Feeley - Assistant Professor, Department of Special Education and Literacy, C. W. Post Campus of Long Island University, 720 Northern Boulevard, Brookville, New York 11548.

\section{Acknowledgements}

This paper is based on a keynote presentation made to the 4th International Conference on Developmental Issues in Down Syndrome, Portsmouth UK, September, 2005. We would like to thank Dr. Joe E. Reichle and Dr. Edward G. Carr for their scholarly critiques of the manuscript.

\section{References}

Baer, D.M., Wolf, M.M. \& Risley, T.R. (1968). Some current dimensions of applied behavior analysis. Journal of Applied Behavior Analysis, 1, 91-97.

Bambara, L.M., Koger, F., Katzer, T. \& Davenport, T.A. (1995). Embedding choice in the context of daily routines: An experimental case study. Journal of the Association for Persons with Severe Handicaps, 20, 15-195.

Brooks, A., Todd, A.W., Tofflemoyer, S. \& Horner, R.H. (2003). Use of functional assessment and a self-management system to increase academic engagement and work completion. Journal of Positive Behavior Interventions, 5 , 144-152.

Buckley, S.J., Bird, G., Sacks, B. \& Archer, T. (2002). A comparison of mainstream and special education for teenagers with Down syndrome: Implications for parents and teachers. Down Syndrome News and Update, 2(2), 46-53

Carr, E.G. \& Durand, M. (1985). Reducing behavior problems through functional communication training. Journal of Applied Behavior Analysis, 18, 111-126.

Carr, E.G., Horner, R.H., Turnbull, A.P., Marquis, J., Magito-McLaughlin, D., McAtee, M.L., Smith, C.E., Anderson-Ryan, K., Ruef, M.B. \& Doolabh, A. (1999). Positive behavior support for people with developmen- tal disabilities: A research synthesis. Monograph of the American Association on Mental Retardation.

Carr, E.G., Levin, L., McConnachie, G., Carlson, J.I., Kemp, D.C. \& Smith, C. (1994). Communication based intervention for problem behavior: A user's guide for producing positive change. Baltimore, MD: Paul H. Brookes.

Carr, E.G., Dunlap, G., Horner, R.H., Koegel, R.L., Turnbull, A.P., Sailor, W., Anderson, J.L., Albin, R.W., Koegel, L.K. \& Fox, L. (2002). Positive behavior support: Evolution of an applied science. Journal of Positive Behavior Interventions, 4, 4-16

Coe, D.A., Matson, J.L., Russell, D.W., Slifer, K.J., Capone, G.T., Baglio, C. \& Stallings, S. (1999). Behavior problems of children with Down syndrome and life events. Journal of Autism and Developmental Disorders, 39, 149-156.

Cole, C.L. \& Levinson T.R. (2002). Effects of within-activity choices on the challenging behavior of children with severe developmental disabilities. Journal of Positive Behavior Interventions, 4, 29-37.

Cooper, J.O., Heward, T.E. \& Heron, W.L. (1987). Applied behavior analysis. Upper Saddle River, NJ: Merril.

Cunningham, C.C., Glenn, S., Lorenz, S., Cuckle, P. \& Shepperdson, B. (1998). Trends and outcomes in educational placements for children with Down syndrome. European Journal of Special Needs Education, 13, 225-237.

Dadson, S. \& Horner, R.H. (1993). Manipulating setting events to decrease problem behavior: A case study. Teaching Exceptional Children, 25, 53-55.

Davis, C.A., Brady, M.P., Williams, R.E. \& Hamilton, R. (1992). Effects of high-probability requests on the acquisition and generalization of responses to requests in young children with behavior disorders. Journal of Applied Behavior Analysis, 25, 905-916.

Davis, C., Brady, M.P., McEvoy, M. \& Williams, R.E. (1994). Effects of high probability request sequences on the social interactions of young children with severe disabilities. Journal of Applied Behavior Analysis, 27, 619-637.

Davis, C., McEvoy, M. \& Reichle, J. (2005). Minnesota Behavioral Support Project. Retrieved April 14, 2006, from http://education.umn.edu/ceed/projects/preschoolbehavior/strategies/mbsp.pdf.

Davis, C.A. \& Reichle, J. (1996). Variant and invariant highprobability requests: Increasing appropriate behaviors in children with emotional-behavioral disorders. Journal of Applied Behavior Analysis, 29, 471-481.

Davis, C.A., Reichle, J. \& Johnston, S. (1998). Teaching children with severe disabilities to utilize nonobligatory conversational opportunities: An application of highprobability requests. The Journal of the Association for Persons with Severe Handicaps, 23, 57-68.

Davis, C.A., Reichle, J.E. \& Southard, K.L. (2000). Highprobability requests and preferred items as a distractor: Increasing successful transitions in children with behavior problems. Education and Treatment of Children, 23, 423-440.

Doss, S. \& Reichle, J. (1991). Replacing excess behavior with an initial communicative repertoire. In J. Reichle, J. York \& J. Sigafoos (Eds.). Implementing augmentative and alternative communication strategies for learners with 
severe disabilities (pp. 215-237). Baltimore, MD: Paul H. Brookes.

Dunlap, G., DePerczel, M., Clarke, S., Wilson, D., Wright, S., White, R. \& Gomez, A. (1994). Choice making to promote adaptive behavior for students with emotional and behavioural challenges. Journal of Applied Behavior Analysis, 27, 505-518.

Durand, V.M. \& Carr, E.G. (1991). Functional communication training to reduce challenging behavior: Maintenance and application in new settings. Journal of Applied Behavior Analysis, 24, 251-264.

Durand, V.M. \& Carr, E.G. (1992). An analysis of maintenance following functional communication training. Journal of Applied Behavior Analysis, 25, 777-794.

Dyer, K., Dunlap, G. \& Winterling, V. (1990). Effects of choice making on the serous problem behaviors of students with severe handicaps. Journal of Applied Behavior Analysis, 23, 515-524.

Dykens, E.M. (1995). Measuring behavioural phenotypes: Provocation from the "new genetics." American Journal on Mental Retardation, 99, 522-532.

Dykens, E. M. \& Kasari, C (1997). Maladaptive behavior in children with Prader-Willi syndrome, Down syndrome, and nonspecific mental retardation. American Journal on Mental Retardation, 102, 228-237.

Evans, D.W. \& Gray, F.L. (2000). Compulsive-like behavior in individuals with Down syndrome: Its relation to mental age level, adaptive and maladaptive behavior. Child Development, 71, 288-300.

Fidler, D.J. (2005). The emerging Down syndrome behavioural phonotype in early childhood: Implications for practice. Infants and Young Children, 18, 86-103.

Gibson, D. (1978). Down's Syndrome: The Psychology of Mongolism. Cambridge: Cambridge University Press.

Glenn, S.M. \& Cunningham, C.C. (2000). Parents' reports of young people with Down syndrome talking out loud to themselves. Mental Retardation, 38, 498-505.

Hall, A.M., Neuharth-Pritchett, S. \& Belfiore, P.J. (1997). Reduction of aggressive behaviors with changes in activity: Linking descriptive and experimental analysis. Education and Training in Mental Retardation and Developmental Disabilities, 32, 331-339.

Hetzroni, O.E. \& Roth, T. (2003). Effects of a positive support approach to enhance communicative behaviors of children with mental retardation who have challenging behaviors. Education and Training in Developmental Disabilities, 38, 95-105.

Horner, R., Day, M., Sprague, J., O’Brien, M. \& Heathfield, L. (1991). Interspersed requests: A nonaversive procedure for reducing aggression and self-injury during instruction. Journal of Applied Behavior Analysis, 24, $265-278$.

Horner, R.H., Vaughn, B.J., Day, H.M. \& Ard, W.R (1996). The relationship between setting events and problem behavior: expanding our understanding of heavier support. In L.K. Koegel \& G. Dunlap (Eds.), Positive Behavioural Support Including People with Difficult Behavior in the Community (pp. 381-402). Baltimore, MD: Paul H. Brooks.

Individuals with Disabilities Education Improvement Act of 2004, Public Law 108-446.
Iwata, B.A., Dorsey, M.F., Slifer, K.J., Bauman, K.W. \& Richman, G.S. (1982). Toward a functional analysis of self-injury. Analysis and Intervention in Developmental Disabilities, 2, 3-20.

Kasari, C. \& Freeman, S.F.N. (2001). Task-related social behavior in children with Down syndrome. American Journal on Mental Retardation, 106, 253-264.

Kern, L., Choutka, C.M. \& Sokol, N.G. (2002). Assessmentbased interventions used in natural settings to reduce challenging behaviors: A review of the literature. Education and Treatment of Children, 25, 113-134.

Mace, F.C. \& Belfiore, P. (1990). Behavioural momentum in the treatment of escape-motivated stereotypy. Journal of Applied Behavior Analysis, 23, 507-514.

Mace, F.C., Hock, M.L., Lalli, J.S., West, B.J., Belfiore, P., Pinter, E. \& Brown, D.K. (1988). Behavioural momentum in the treatment of noncompliance. Journal of Applied Behavior Analysis, 21, 123-141.

Marcus, B.A. \& Vollmer, T.R. (1996). Combining noncontingent reinforcement and differential reinforcement schedules as treatment for aberrant behavior. Journal of Applied Behavior Analysis, 29, 43-51.

McGill, P. (1999). Establishing operations: Implications for the assessment, treatment and prevention of problem behavior. Journal of Applied Behavior Analysis, 32, 393418.

McGill, P., Teer, K., Rye, L. \& Hughes, D. (2005). Staff reports of setting events associated with challenging behavior. Behavior Modification, 28, 599-615.

McComas, J.J., Thompson, A. \& Johnson, L. (2003). The effects of presession attention on problem behavior maintained by different reinforcers. Journal of Applied Behavior Analysis, 36, 297-307.

Michael, J. (1982). Distinguishing between discriminative and motivational functions of stimuli. Journal of the Experimental Analysis of Behavior, 37, 149-155.

Michael, J. (2000). Implications and refinements of the establishing operation concept. Journal of Applied Behavior Analysis, 33, 401-410.

O’Neill, R.E., Horner, R.H., Albin, R.W., Storey, K. \& Sprague, J.R. (1997). Functional Assessment and Program Development for Problem Behavior: A Practical Handbook ( $2^{\text {nd }}$ ed.). Pacific Grove, CA: Brooks/Cole.

Pitcairn, T.K. \& Wishart, J.G. (1994). Reaction of young children with Down's syndrome to an impossible task. British Journal of Developmental Psychology, 12, 485-489.

Repp, A.C., Deitz, S.M. \& Speir, N.C. (1974). Reducing stereotypic responding of retarded persons by differential reinforcement of other behavior. American Journal of Mental Deficiency, 79, 279-284.

Repp, A.C. \& Karsh, D. (1994). A hypothesis-based interventions for tantrum behavior of person with developmental disabilities in school settings. Journal of Applied Behavior Analysis, 27, 21-31.

Richdale, A., Francis, A., Gavidia-Payne, S. \& Cotton, S. (2000). Stress, behavior, and sleep problems in children with an intellectual disability. Journal of Intellectual and Developmental Disability, 25, 147-161.

Roizen, N.J. (1996). Down syndrome and associated medical disorders. Mental Retardation and Developmental Disability Research Reviews, 2, 85-89. 
K.M. Feeley and E.A. Jones $\cdot$ Challenging behaviour in children with Down syndrome

Singer, G.H.S., Singer, J. \& Horner, R.H. (1987). Using pretask requests to increase the probability of compliance for students with severe disabilities. Journal of the Association for Persons with Severe Handicaps, 12, 287-291.

Stores, R. (1993). A preliminary study of sleep disorders and daytime behavior problems in children with Down's syndrome. Down Syndrome Research and Practice, 1, 29-33.

Stores, R. \& Stores, G. (1996). Research on sleep problems and psychological function in children with Down syndrome: Implication for clinical practice and everyday care. Down Syndrome Research and Practice, 4, 110-112.

Wahler, R. G. \& Fox, J. J. (1981). Setting events in applied behavior analysis: Toward a conceptual and methodological expansion. Journal of Applied Behavior Analysis, 14, 327-338.

Wishart, J. (1993a). The development of learning difficulties in children with Down's syndrome. Journal of Intellectual Disability Research, 37, 389-403.

Wishart, J. (1993b). Learning the hard way: Avoidance strategies in young children with Down's syndrome. Down Syndrome Research and Practice, 1, 47-55.

Wishart, J.G. (1986). The effects of step-by-step training on cognitive performance in infants with Down's syndrome. Journal of Mental Deficiency Research, 30, 233-250.

Wishart, J.G. \& Duffy, L. (1990). Instability of performance on cognitive tests in infants and young children with Down's syndrome. British Journal of Educational Psychology, 59, 10-22. 